\title{
Caracterização dos óbitos por malformações congênitas no sistema nervoso entre 2000 e 2017 no Brasil
}

Characterization of deaths due to congenital malformations in the nervous system between 2000 and 2017 in Brazil

Caracterización de muertes por malformaciones congénitas en el sistema nervioso entre 2000 y 2017 en Brasil

Mateus Sousa CAVALCANTE(1) Glaucia Galindo SILVA ${ }^{(2)}$

Érica Santos ROCHA ${ }^{(2)}$ Jardel Barbosa da SILVA ${ }^{(2)}$ Thayná Rocha COIMBRA(2) Allan Cristhyan Alves CARVALHO(1) Bruno Luciano Carneiro Alves de OLIVEIRA ${ }^{(3)}$

Recebido: 1 maio 2020

Revisado: 8 set 2020

Aceito: 13 out 2020

Autor de correspondência: Mateus de Sousa Cavalcante mateus.sousa.cav@gmail.com

Conflito de interesses: Os autores declaram não haver nenhum interesse profissional ou pessoal que possa gerar conflito de interesses em relação a este manuscrito.

\section{Resumo}

No Brasil, distúrbios genéticos são a segunda maior causa de mortalidade infantil, e os defeitos do sistema nervoso (SN) correspondem a 18,8\% deles. Este estudo buscou caracterizar os óbitos por Malformações Congênitas no Sistema Nervoso - MCSN entre 2000 e 2017 no Brasil. Trata-se de estudo transversal com dados de óbitos por MCSN de 2000 a 2017. Foram analisadas as variáveis idade, sexo e cor/raça do óbito da criança, e a idade, escolaridade e tipo de parto da mãe, região do país, e quais as principais malformações. Diferenças estatísticas foram verificadas por meio do teste de Qui-quadrado de Pearson e consideradas significantes quando o $p$-valor $<0,05$. No período avaliado, foram registrados 29.641 óbitos por MCSN e o número de casos vem reduzindo. A hidrocefalia foi a causa mais frequente, seguida da microcefalia. Óbitos relacionados à microcefalia tiveram pico súbito de crescimento durante o período de epidemia do Zika. A maioria dos casos de óbitos por microcefalia nos anos analisados $(86,0 \%)$ foram em crianças menores de um ano de idade. As variáveis sociodemográficas: sexo, raça e região demonstraram-se estatisticamente significantes $(p$-valor $<0,05)$. A região Sudeste apresentou maior proporção $(34,8 \%)$, seguido do Nordeste $(30,4 \%)$. A maioria dos óbitos foi em meninas $(52,1 \%)$, brancos $(56,0 \%)$ e nasceram de parto cesáreo $(64,1 \%)$. 
Predominaram casos em mães na faixa etária de 19 a 35 anos (74,6\%), seguido de mães mais jovens (19 anos $=17,1 \%$ ). Também houve predominância de casos quando a mãe possuía escolaridade de 4 a 11 anos (72,1\%). Observou-se que ainda há grande ocorrência de óbitos por MCSN e estes ainda são maiores que outros países. Esses dados podem refletir a baixa adesão ao pré-natal e cuidados gestacionais, assim como geram questões importantes sobre ao desenvolvimento infanto-juvenil no país.

Descritores: Anormalidades Congênitas; Sistema Nervoso; Epidemiologia.

\section{Abstract}

In Brazil, genetic disorders are the second leading cause of infant mortality, and defects in the nervous system (NS) correspond to $18.8 \%$ of them. This study sought to characterize deaths due to Congenital Malformations in the Nervous System - CMNS between 2000 and 2017 in Brazil. This is a crosssectional study with data on deaths from CMNS from 2000 to 2017. The variables analyzed were age, sex and color / race of the child's death, and the mother's age, education and type of delivery, region of the country, and what are the main malformations. Statistical differences were verified using Pearson's Chi-Square Test and considered significant when the $p$-value $<0.05$. In the evaluated period, 29,641 deaths due to CMNS were registered and the number of cases has been reduced. Hydrocephalus was the most frequent cause, followed by microcephaly. Deaths related to microcephaly had a sudden peak of growth during the Zika epidemic period. Most cases of microcephaly in the years analyzed (86.0\%) were in children under one year of age. Sociodemographic variables: sex, race and region were statistically significant ( $p$-value $<0.05$ ). The Southeast region had the highest proportion (34.8\%), followed by the Northeast (30.4\%). Most deaths were in girls (52.1\%), white $(56.0 \%)$ and were born by cesarean (64.1\%). Cases predominated in mothers aged 19 to 35 years $(74.6 \%)$, followed by younger mothers (19 years $=17.1 \%)$. There was also a predominance of cases when the mother had 4 to 11 years of schooling (72.1\%). It was observed that there is still a high occurrence of deaths due to CMNS and these are still greater than other countries. These data may reflect the low adherence to prenatal and pregnancy care, as well as generate important questions about child and adolescent development in the country.

Keywords: Congenital Abnormalities; Nervous System; Epidemiology.

\section{Resumen}

En Brasil, los trastornos genéticos son segunda causa principal de mortalidad infantil, y los defectos en el sistema nervioso (SN) corresponden al 18,8\% de ellos. Este estudio buscó caracterizar las muertes debidas a Malformaciones Congénitas en Sistema Nervioso - MCSN entre 2000 y 2017 en Brasil. Es un estudio transversal con datos sobre muertes por MCSN entre 2000 y 2017 . Se analizaron las variables edad, sexo y color / raza de la muerte del niño, y edad de la madre, educación y tipo de parto, región del país, y cuáles son las principales malformaciones. Diferencias estadísticas se verificaron mediante la prueba de chi-cuadrado de Pearson y se consideraron significativas cuando el valor $p<0,05$. En el período evaluado, se registraron 29.641 muertes debido a MCSN y se redujo el número de casos. Hidrocefalia fue la causa más frecuente, seguida de microcefalia. Las muertes relacionadas con la microcefalia tuvieron un pico repentino de crecimiento durante el período epidémico del Zika. La mayoría de los casos de microcefalia em los años analizados $(86,0 \%)$ fueron en niños menores de un año de edad. Las variables sociodemográficas: sexo, raza y región fueron estadísticamente significativas (valor $\mathrm{p}<0.05)$. La región sudeste tuvo la mayor proporción $(34,8 \%)$, seguida por noreste (30,4\%). La mayoría de las muertes fueron en niñas $(52,1 \%)$, blancas $(56,0 \%)$ y nacieron por parto por cesárea (64,1\%). Los casos predominaban en madres de 19 a 35 años (74,6\%), seguidas de madres más jóvenes (19 años $=17,1 \%$ ). También hubo predominio de casos cuando la madre tenía entre 4 y 11 años de escolaridad (72,1\%). Se observó que todavía hay una alta incidencia de muertes debido MCSN y estas son aún mayores que otros países. Estos datos pueden reflejar la baja adherencia a la atención prenatal y la atención del embarazo, así como generar preguntas importantes sobre el desarrollo de niños y adolescentes em el país.

Palabras-claves: Anomalías Congénitas; Sistema Nervioso; Epidemiología. 


\section{Introdução}

Segundo a Organização Pan-Americana de Saúde - OPAS, ${ }^{1}$ as malformações congênitas estão associadas à ideia de defeitos na formação de determinado órgão ou conjunto de órgãos, determinando uma anomalia morfológica estrutural que se manifesta logo ao nascimento ou tardiamente. ${ }^{1}$ Tal definição abrange todos os desvios em relação ao formato, dimensão, posicionamento, número e coloração de uma ou mais partes capazes de serem averiguadas em dimensão macroscópica. $\mathrm{O}$ agente etiológico pode ser um fator genético, ambiental ou múltiplos.

As anomalias congênitas se manifestam, na maioria das vezes, em um único sistema, porém, também, podem ser observados casos de malformações múltiplas, o que constitui uma síndrome e diminui drasticamente a chance de sobrevida do neonato e até a manutenção da gestação. ${ }^{2}$ Segundo a literatura médica, as anomalias congênitas são uma das principais causas de mortalidade ao longo do primeiro ano de vida. ${ }^{3}$

As Malformações Congênitas no Sistema Nervoso - MCSN têm uma significativa prevalência: atingindo de 1 a 10/1.000 dos nascidos vivos. De acordo com a literatura, ${ }^{4}$ estima-se que $31,8 \%$ entre todas as malformações congênitas são relacionadas ao Sistema Nervoso Central - SNC. ${ }^{4}$ Tais distúrbios podem ser agrupados em defeitos do tubo neural e da medula espinal, especificação de estruturas (migração neuronal e substância cinzenta), crescimento e tamanho do cérebro e crescimento e tamanho do crânio. Ainda, dentre os fatores precipitantes, destacam-se anormalidades cromossômicas, metabólicas e genéticas, infecções (toxoplasmose, rubéola, citomegalovírus, herpes), exposição a medicamentos, hipovitaminoses, sustâncias teratogênicas, irradiação, álcool e drogas. ${ }^{5}$

Os defeitos do fechamento do tubo neural (DFTN) são os que mais resultam em MCSN, e ocorrem quando há falha no fechamento adequado do tubo neural embrionário, no período da quarta semana de embriogênese. ${ }^{6}$ Tais malformações têm alta gravidade e morbimortalidade, o que evidencia a necessidade no pré-natal do diagnóstico precoce, aconselhamento genético, suplementação dietética com ácido fólico, dentre outras formas de prevenção ou tratamento. ${ }^{7}$

No ano de 2015, ocorreu uma elevada incidência de microcefalia no Brasil. Tal fato levou ao surgimento de diversas pesquisas sobre malformações congênitas, sendo, por fim, inferida a sua relação direta com a epidemia do Zika virus que ocorreu no mesmo período. ${ }^{8}$ Desde essa época, tem-se observado aumento do interesse da comunidade científica em estudar as malformações congênitas no SNC. Contudo, atualmente, ainda se têm várias malformações pouco conhecidas e explicadas, por conseguinte, pouco diagnosticadas e com escassez de métodos de prevenção e tratamento. 
ISSN 2179-6750

Dessa forma, observa-se poucos estudos que descrevem mais amplamente a situação epidemiológica das MCSN, o que limita a construção de estratégias para o seu manejo, prevenção e atenção à saúde. Nesse sentido, o presente estudo buscou caracterizar os óbitos por malformações congênitas no sistema nervoso entre 2000 e 2017 no Brasil.

\section{Metodologia}

Trata-se de estudo transversal construído a partir de dados secundários disponíveis online pelo Sistema de Informações sobre Mortalidade - SIM do Departamento de Informática do Sistema Único de Saúde - DATASUS, disponibilizado pelo Ministério de Saúde do Brasil. Foram utilizados dados de óbitos por MCSN (Código Internacional de Doenças - 10 ed. - CID.10: Q048) ocorridos no Brasil entre os anos de 2000 e 2017 em crianças menores de 10 anos de idade. As variáveis examinadas foram: idade, sexo e cor/raça do óbito da criança, e a idade, escolaridade e tipo de parto da mãe, região do país, e por fim, quais as principais malformações que ocorreram. Para estes aspectos, utilizou-se a análise com base no CID e posterior avaliação das causas básicas desses tipos de óbitos.

Os dados foram coletados no período de junho de 2019. Elaboraram-se tabelas e gráficos a partir dos dados adquiridos. Associações estatísticas foram verificadas por meio do teste de Qui-quadrado de Pearson e consideradas significantes quando o $\mathrm{p}$ valor $<0,05$. Todas as análises foram realizadas com o auxílio dos softwares Stata ${ }^{\circledR}$ versão 14 (StataCorp LP, College Station, Texas, Estados Unidos).

O presente estudo foi elaborado exclusivamente com dados secundários agregados de óbitos obtidos das bases de dados do Ministério da Saúde de acesso público. As bases de dados consultadas não contemplam informações sigilosas de identificação pessoal (nomes e números de documentos) ou de domicílio (endereço), o que garante o respeito ao sigilo e à privacidade sobre as informações dos sujeitos envolvidos. Assim, tornou-se dispensada a aprovação do estudo por um comitê de ética em pesquisa. Todo o trabalho foi realizado em conformidade com a Resolução do Conselho Nacional de Saúde - CNS n. 510, de 07 de abril de 2016 e suas complementares. ${ }^{9}$

\section{Resultados}

Entre os anos de 2000 e 2017 foram registrados 29.641 óbitos por MCSN, no SIM. A maioria dos casos (85,9\%) foram em crianças menores de um ano de idade enquanto a menor foi entre cinco e nove anos (3,9\%). Quando distribuídos por regiões 
do Brasil, a região Sudeste apresentou maior proporção $(34,8 \%)$ de óbitos, seguido do Nordeste $(30,4 \%)$ e Sul $(13,8 \%)$, e a menor foi no Norte $(12,1 \%)$ e Centro-Oeste (8,8\%). Em relação ao sexo, 52,1\% eram de meninas. Do total de 25.189 óbitos, 56,0\% ocorreram em crianças declaradas com a cor branca; 40,5\% nos declarados pardos; e somente 2,2\% nos declarados pretos. Quanto ao tipo de parto, 64,1\% nasceram de parto cesáreo, enquanto $35,9 \%$ de parto normal. Predominaram casos em mães na faixa etária de 19 a 35 anos (74,6\%), seguido de mães menores que 19 anos (17,1\%) e maiores que 35 anos (8,3\%). Também houve predominância de casos quando a mãe possuía escolaridade de 4 a 11 anos (72,1\%). Observou-se ainda que 17,5\% dos casos tinham mães com escolaridade de 0 a 3 anos e 10,4\%, mães com escolaridade maior que 12 anos. As variáveis sociodemográficas: sexo, raça/cor e região demonstraram-se associadas estatisticamente ( $p$-valor $<0,05)$ (Tabela 1$)$.

Tabela 1. Características dos óbitos por Malformações Congênitas no Sistema Nervoso segunda a idade no Brasil entre 2000 e 2017

\begin{tabular}{|c|c|c|c|c|c|c|c|c|c|}
\hline \multirow[t]{3}{*}{ Variáveis } & \multicolumn{6}{|c|}{ Faixa Etária } & \multirow{2}{*}{\multicolumn{2}{|c|}{ Total }} & \multirow[t]{3}{*}{ p-valor* } \\
\hline & \multicolumn{2}{|c|}{$<1$ ano } & \multicolumn{2}{|c|}{1 a 4 anos } & \multicolumn{2}{|c|}{5 a 9 anos } & & & \\
\hline & $\mathrm{n}$ & $\%$ & $\mathrm{n}$ & $\%$ & $\mathrm{n}$ & $\%$ & $\mathrm{~N}$ & $\%$ & \\
\hline Sexo & 25.280 & 85,9 & 2.994 & 10,2 & 1.144 & 3,9 & 29.418 & 100 & \\
\hline Masculino & 12.036 & 85,4 & 1.493 & 10,6 & 570 & 4,0 & 14.099 & 100 & 0,028 \\
\hline Feminino & 13.244 & 86,4 & 1.501 & 9,8 & 574 & 3,8 & 15.319 & 100 & \\
\hline Raça/Cor & 21.379 & 84,8 & 2.760 & 11,0 & 1.050 & 4,2 & 25.189 & 100 & \\
\hline Branco & 11.751 & 83,3 & 1.710 & 12,1 & 641 & 4,6 & 14.102 & 100 & 0,000 \\
\hline Preto & 434 & 78,1 & 76 & 13,6 & 46 & 8,3 & 556 & 100 & \\
\hline Pardo & 8.900 & 87,4 & 938 & 9,2 & 351 & 3,4 & 10.189 & 100 & \\
\hline $\begin{array}{l}\text { Amarelo e } \\
\text { Indígena }\end{array}$ & 294 & 86,0 & 36 & 10,5 & 12 & 3,5 & 342 & 100 & \\
\hline Tipo de Parto & 21.555 & 99,9 & 28 & 0,1 & 0 & 0,0 & 21.583 & 100 & \\
\hline Normal & 7.730 & 99,9 & 11 & 0,1 & 0 & 0,0 & 7.741 & 100 & 0,658 \\
\hline Cesáreo & 13.825 & 99,9 & 17 & 0,1 & 0 & 0,0 & 13.842 & 100 & \\
\hline Região & 25.503 & 86,0 & 2.994 & 10,1 & 1.144 & 3,9 & 29.641 & 100 & \\
\hline Norte & 3.173 & 88,2 & 332 & 9,2 & 92 & 2,6 & 3.597 & 100 & 0,000 \\
\hline Nordeste & 7.916 & 87,9 & 785 & 8,7 & 304 & 3,4 & 9.005 & 100 & \\
\hline Centro-Oeste & 2.229 & 85,2 & 287 & 11,0 & 100 & 3,8 & 2.616 & 100 & \\
\hline Sudeste & 9.837 & 85,6 & 1.060 & 10,3 & 425 & 4,1 & 10.322 & 100 & \\
\hline Sul & 3.348 & 81,6 & 530 & 12,9 & 223 & 5,4 & 4.101 & 100 & \\
\hline Idade da Mãe & 20.525 & 99,9 & 26 & 0,1 & 0 & 0,0 & 20.551 & 100 & \\
\hline Até 19 anos & 3.521 & 99,9 & 3 & 0,1 & 0 & 0,0 & 3.524 & 100 & 0,732 \\
\hline Entre 19 e 35 anos & 15.303 & 99,9 & 21 & 0,1 & 0 & 0,0 & 15.324 & 100 & \\
\hline Maior de 35 anos & 1.701 & 99,9 & 2 & 0,1 & 0 & 0,0 & 1.703 & 100 & \\
\hline Escolaridade da Mãe & 18.632 & 99,9 & 28 & 0,1 & 0 & 0,0 & 18.660 & 100 & \\
\hline 0 e 3 anos & 3.254 & 99,8 & 6 & 0,2 & 0 & 0,0 & 3.260 & 100 & 0,815 \\
\hline 4 e 11 anos & 13.445 & 99,9 & 18 & 0,0 & 0 & 0,0 & 13.463 & 100 & \\
\hline$\geq 12$ anos & 1.933 & 99,8 & 4 & 0,2 & 0 & 0,0 & 1.937 & 100 & \\
\hline
\end{tabular}

Notas: *Teste Chi-quadrado de Pearson

Fonte: SIM (2019). ${ }^{10}$ 
Por meio da classificação do CID, foram selecionadas as dez MCSN com maior número de óbitos no Brasil, entre 2000 e 2017. Nessa óptica, predominaram óbitos por hidrocefalia congênita não especificada (Q039), com 18,8\%; seguida de malformação congênita não especificada do encéfalo (Q049), com 6,4\%; outras deformidades por redução do encéfalo (Q043), com 6,0\%; microcefalia (Q02), com 5,4\%; atresia das fendas de Luschka e do forâmen de Magendie (FLFM) (Q031), com $5,0 \%$. As demais causas apresentam menos de 5,0\% dos casos. Foi feita a comparação dos óbitos segundo a região do Brasil. Os resultados obtidos mostraram que todos os óbitos decorrentes das dez MCSN selecionadas tiveram maior predominância nas regiões Nordeste e Sudeste. Na Região Nordeste, observou-se predominância da hidrocefalia congênita não especificada (30,2\%), quando comparada a outras regiões, além das demais: malformação congênita não especificada do encéfalo (33,8\%); atresia FLFM (34,4\%); espinha bífida não especificada (35,7\%); e espinha bífida não especificada com hidrocefalia (33,6\%). Na Região Sudeste houve predomínio de deformidades por redução do encéfalo $(41,0 \%)$, seguida das demais: microcefalia (39,4\%); encefalocele não especificada (31,5\%); holoprosencefalia (50,9\%); e malformação congênita não especificada do sistema nervoso (40,5\%) (Tabela 2).

Além disso, considerando a distribuição de cada uma das malformações entre as regiões, observou-se que a menor predominância variou entre as regiões Norte e Centro-oeste, sendo que apenas atresia FLFM teve menor frequência na região Sul $(9,1 \%)$. Por sua vez, a encefalocele não especificada; espinha bífida não especificada, com hidrocefalia; e holoprosencefalia, tiveram menor número de óbitos na região Norte, com, respectivamente, 99 (9,0\%); 87 (8,51\%); e 55 (6,6\%) óbitos. Por fim, hidrocefalia congênita não especificada, malformação congênita não especificada do encéfalo, outras deformidades por redução do encéfalo, microcefalia, espinha bífida não especificada e malformação congênita não especificada do sistema nervoso tiveram menor predominância na região Centro-oeste (Tabela 2). 
ISSN 2179-6750

Tabela 2. Principais causas gerais de óbitos por Malformações Congênitas no Sistema Nervoso, por região do Brasil entre 2000 e 2017

\begin{tabular}{|c|c|c|c|c|c|c|c|c|c|c|c|c|c|}
\hline \multirow{2}{*}{\multicolumn{2}{|c|}{$\begin{array}{c}\text { Malformações Congênitas do } \\
\text { Sistema Nervoso }\end{array}$}} & \multicolumn{10}{|c|}{ Regiões do país } & \multicolumn{2}{|c|}{ Total } \\
\hline & & \multicolumn{2}{|c|}{ Norte } & \multicolumn{2}{|c|}{ Nordeste } & \multicolumn{2}{|c|}{$\begin{array}{l}\text { Centro- } \\
\text { Oeste }\end{array}$} & \multicolumn{2}{|c|}{ Sudeste } & \multicolumn{2}{|c|}{ Sul } & & \\
\hline Malformação & CID & $\mathrm{n}$ & $\%$ & $\mathrm{n}$ & $\%$ & $\mathrm{n}$ & $\%$ & $\mathrm{n}$ & $\%$ & $\mathrm{n}$ & $\%$ & $\mathrm{~N}$ & $\%$ \\
\hline $\begin{array}{l}\text { Hidrocefalia congênita } \\
\text { não especificada }\end{array}$ & Q039 & 849 & 15,3 & 1680 & 30,2 & 568 & 10,2 & 1581 & 28,4 & 891 & 16 & 5569 & 100 \\
\hline $\begin{array}{l}\text { Malformação congênita } \\
\text { não especificada do } \\
\text { encéfalo }\end{array}$ & Q049 & 268 & 14,1 & 642 & 33,8 & 147 & 7,7 & 573 & 30,2 & 269 & 14,2 & 1899 & 100 \\
\hline $\begin{array}{l}\text { Outras deformidades } \\
\text { por redução do encéfalo }\end{array}$ & Q043 & 266 & 14,9 & 380 & 21,4 & 182 & 10,2 & 729 & 41,0 & 223 & 12,5 & 1780 & 100 \\
\hline Microcefalia & Q02 & 186 & 11,7 & 490 & 30,7 & 158 & 9,9 & 505 & 31,5 & 258 & 16,2 & 1595 & 100 \\
\hline $\begin{array}{l}\text { Atresia das fendas de } \\
\text { Luschka e do forâmen } \\
\text { de Magendie }\end{array}$ & Q031 & 174 & 11,8 & 508 & 34,4 & 192 & 13,0 & 469 & 31,7 & 134 & 9,1 & 1477 & 100 \\
\hline $\begin{array}{l}\text { Espinha bífida não } \\
\text { especificada }\end{array}$ & Q059 & 118 & 8,7 & 485 & 35,7 & 104 & 7,6 & 475 & 34,9 & 178 & 13,1 & 1360 & 100 \\
\hline $\begin{array}{l}\text { Encefalocele não } \\
\text { especificada }\end{array}$ & Q019 & 99 & 9,0 & 330 & 29,9 & 100 & 9,1 & 435 & 39,4 & 139 & 12,6 & 1103 & 100 \\
\hline $\begin{array}{l}\text { Espinha bífida não } \\
\text { especificada, com } \\
\text { hidrocefalia }\end{array}$ & Q054 & 87 & 8,5 & 343 & 33,6 & 91 & 8,9 & 336 & 32,9 & 165 & 16,1 & 1022 & 100 \\
\hline Holoprosencefalia & Q042 & 55 & 6,6 & 140 & 16,7 & 83 & 9,9 & 422 & 50,9 & 137 & 16,4 & 837 & 100 \\
\hline $\begin{array}{l}\text { Malformação congênita } \\
\text { não especificada do } \\
\text { sistema nervoso }\end{array}$ & Q079 & 74 & 8,9 & 235 & 28,3 & 64 & 7,7 & 337 & 40,5 & 122 & 14,7 & 832 & 100 \\
\hline
\end{tabular}

Fonte: SIM (2019). ${ }^{10}$

Ainda com base na classificação do CID, foram analisadas as cinco principais causas de óbitos por MCSN, excluindo os códigos para classificações gerais (a saber: malformação congênita não especificada do encéfalo (Q049) e outras deformidades por redução do encéfalo (Q043)). Entre os anos de 2000 e 2017, a causa de óbito mais frequente foi hidrocefalia, seguida de microcefalia, atresia da fenda de Luschka e do forâmen de Magendie (atresia FLFM), espinha bífida e encefalocele. Os casos de óbitos por hidrocefalia apresentaram-se maiores que as demais causas durante todos os anos analisados, tendo maior incidência no ano de 2005 e menor incidência no ano de 2017. Os casos de óbitos por microcefalia durante os anos em estudo apresentam uma periodicidade, com leves aumentos e reduções de incidências alternadas entre os anos, até 2015, neste momento, porém, houve aumento súbito dos casos que passam de 93 óbitos por ano para 200 óbitos em 2016. No ano seguinte, reduz para 140 óbitos. O número de óbitos por atresia FLFM apresenta seu maior pico no ano de 2002 com 118 casos e sua menor incidência em 2014 
ISSN 2179-6750

com 56 casos. Já os casos de óbitos devido a espinha bífida tiveram maior número em 2001 e pode-se observar tendência a redução da incidência ao longo dos anos, apresentando a menor ocorrência no ano de 2015. Os óbitos relacionados à encefalocele apresentaram-se em maior número no ano de 2003 com 88 casos e menor número em 2006 com 43 casos. Nota-se uma periodicidade entre aumento e redução da incidência de óbitos ao longo dos anos, não havendo diferenças significativas entre os primeiros e os últimos anos (Gráfico 1).

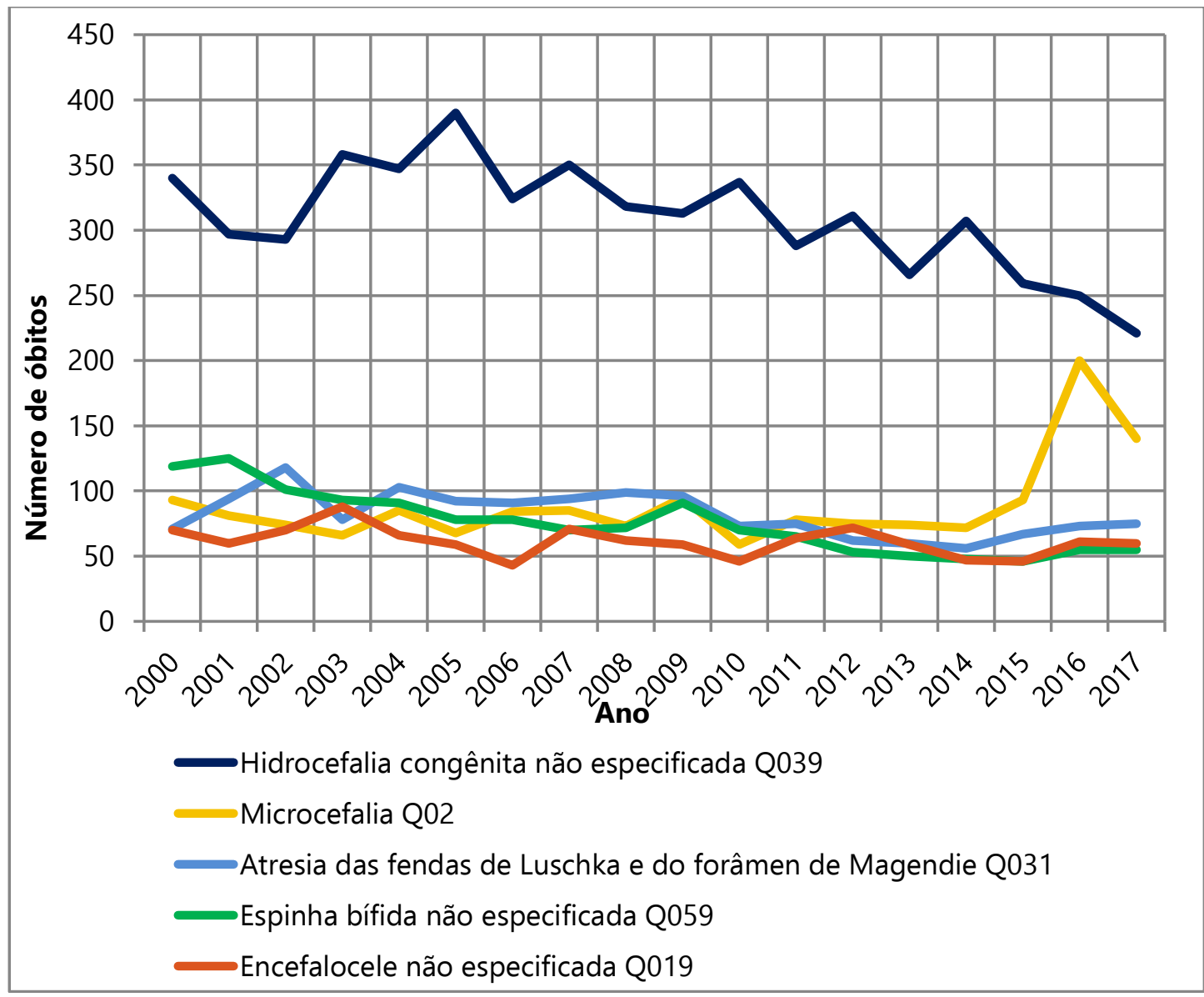

Gráfico 1. Principais Causas Específicas de Óbitos por Malformações Congênitas no Sistema Nervoso no Brasil entre 2000 e 2017

Fonte: SIM (2019). ${ }^{10}$ 
ISSN 2179-6750

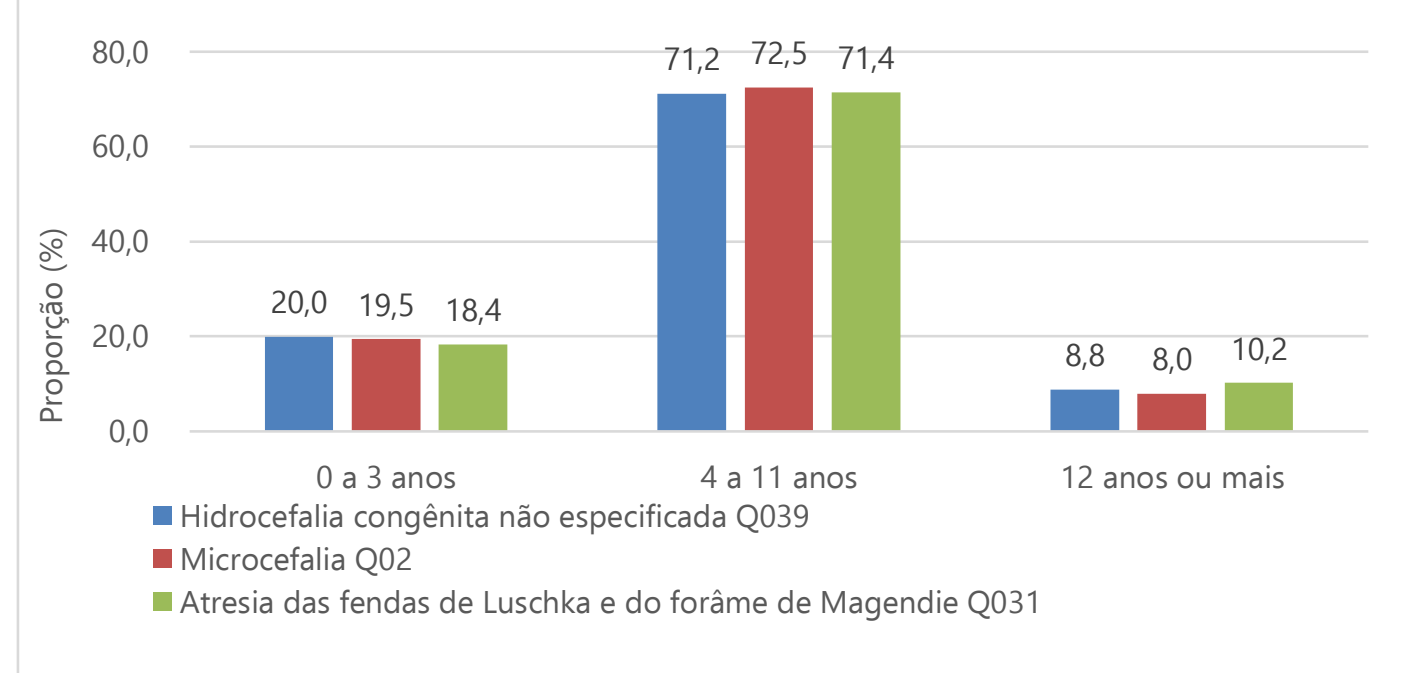

Gráfico 2. Principais Causas Específicas de Óbitos por Malformações Congênitas do Sistema Nervoso segundo nível de escolaridade materna no Brasil entre 2000 e 2017

Notas: *Teste Chi-quadrado de Pearson. * $\mathrm{p}$-valor $=0,451$.

Fonte: SIM (2019). ${ }^{10}$

Foram selecionadas as três principais MCSN em ordem decrescente de número de óbitos, excluindo-se, contudo, aqueles CIDs que descreviam malformações mais generalizadas, com o objetivo de analisar possíveis relações estatísticas. Nesse sentido, as malformações selecionadas foram hidrocefalia não especificada (Q039); microcefalia (Q02); e atrésia FLFM (Q031). Não foi observada diferença estatisticamente significativa entre as três classes de escolaridade, quando relacionadas aos óbitos ( $p$-valor=0,451). Observou-se que a morte por hidrocefalia predominou em todas as classes de escolaridade da mãe. Houve diminuição abrupta dos óbitos na terceira classe de escolaridade da mãe quando comparada à segunda classe, somando-se ao fato de que os números de óbitos por MCSN da escolaridade da mãe de 12 anos ou mais atingiram os menores valores dentre as demais (Gráfico 2).

\section{Discussão}

Os resultados apontaram grande ocorrência de óbitos por MCSN no Brasil e estes ainda são maiores que outros países. Verificou-se associação estatisticamente significante das variáveis sociodemográficas materno-infantis ao óbito por MCSN. Houve um maior número de óbitos no sexo feminino, raça/cor branca e entre aqueles que viviam na região Sudeste do Brasil. Além disso, observou-se maior incidência de óbitos em menores de um ano de idade para todas as variáveis analisadas. Quanto às regiões do Brasil, o Nordeste e Sudeste apresentaram maior incidência de óbitos. No período estudado, a hidrocefalia 
ISSN 2179-6750

representou a causa mais frequente de óbitos por MCSN, seguido de microcefalia e atresia FLFM. A hidrocefalia, apesar de apresentar elevada ocorrência, vem apresentando tendência à redução ao longo dos anos. Em contrapartida, os óbitos relacionados à microcefalia obtiveram um pico súbito de crescimento a partir de 2014 que coincide com o período de epidemia do Zika virus no Brasil.

No que tange à variável sexo, notou-se que os óbitos por MCSN foram mais incidentes no sexo feminino. Essa relação já foi outrora constatada por outro estudo, o qual verificou que as doenças congênitas possuem maior incidência no sexo feminino. ${ }^{11}$ É interessante citar que existe uma contradição entre o número de nascidos vivos de cada sexo, visto que há maior número destes relacionados ao sexo masculino, ${ }^{10}$ porém vê-se maior número de óbitos por malformações congênitas no sexo feminino. Esta contradição pode ser explicada pelo fato de o sexo feminino necessitar de quantidades maiores do hormônio gonadotrofina coriônica humana do que o sexo masculino para que ocorra o fechamento do tubo neural e o desenvolvimento saudável do feto não seja prejudicado. ${ }^{12}$

Em relação à idade materna, observou-se maior predominância de óbitos por MCSN nas crianças em que suas mães tinham idade entre 19 a 35 anos. Resultados semelhantes já foram relatados em outro estudo, onde constatou-se maior predomínio de óbitos por malformações congênitas em nascidos vivos de mulheres adultas. ${ }^{13}$ Entretanto há autores que não relacionam, estatisticamente, idade materna e anomalias congênitas como fatores associados. ${ }^{14}$ É válido citar que, segundo o Sistema de Informações sobre Nascidos Vivos, entre 2000 e 2017, o maior número de nascidos vivos foi apresentado quando a idade materna se encontra entre 20 e 34 anos, $^{11}$ o que coincide com a faixa etária com maior número de óbitos por malformação congênita do sistema nervoso.

No que diz respeito à raça/cor, verificou-se que brancos têm maior proporção de MCSN que os demais grupos raciais. Um estudo realizado no município do Rio de Janeiro constatou que as malformações congênitas do sistema nervoso estão mais presentes na raça branca, no local estudado, e que tal fato deve advir como consequência de diferentes predisposições genéticas complexas interagindo com os fatores ambientais. ${ }^{15}$

Ademais, notou-se uma maior incidência de óbitos relacionados ao parto cesáreo. Tal fato pode ser explicado pelas recomendações direcionadas às mães para realização do parto em questão. Amorim et al. ${ }^{16}$ trouxe os diversos tipos e graus de recomendações para esse processo cirúrgico, no qual as malformações congênitas se encontram como grau $B$, ou seja, possuem alta indicação caso o feto seja diagnosticado precocemente. ${ }^{15}$ Essa recomendação é baseada em consenso e opinião de especialistas, ${ }^{17}$ sendo comum que diagnósticos precoces de malformações congênitas, incluindo as relacionadas ao sistema nervoso, sejam direcionados ao procedimento cesáreo, influenciando as estatísticas então apresentadas 
ISSN 2179-6750

pelo presente estudo. Outro dado importante é abordado por Eckstein, ${ }^{18}$ o qual retrata que os partos cesáreos chegam a cerca de $40 \%$ do total na rede pública, e a quase $85 \%$ na rede complementar, fato o qual também pode influenciar os dados achados nesse estudo.

Quando se observa a relação entre as principais MCSN e as regiões de maior incidência de óbitos, destacam-se o Nordeste e Sudeste. É importante salientar que provavelmente há uma relação, não única, dos óbitos por região e tamanho populacional de cada uma dessas, visto que, de acordo com o Institu to Brasileiro de Geografia e Estatística - IBGE, ${ }^{19}$ a população do nordeste somada à da região Sudeste chega a representar cerca de $70 \%$ da população.

A partir da análise dos dados pesquisados, observou-se que a incidência de óbitos por hidrocefalia apresentou comportamento cíclico, oscilando ao longo dos anos entre picos de crescimento e redução com tendência à diminuição de caso nos últimos anos. Apesar de terem ocorrido quatro picos em 2007; 2010; 2012; e 2014, os números de óbitos diminuíram desde 2005. Além disso, a partir de 2014 a frequência decaiu sem a ocorrência de novos picos, até 2017, último ano abrangido pela pesquisa. Além da hidrocefalia, os óbitos por atresia FLFM e por espinha bífida também apresentaram diminuição de casos. Os óbitos relacionados à Encefalocele pouco variaram ao longo dos anos, cuja linha de crescimento tendeu para uma estabilidade.

Dal Fabbro ${ }^{20}$ demonstra que as causas para as doenças supracitadas podem estar relacionadas com os DFTN devido à interferência de fatores genéticos e/ou ambientais como a carência de ácido fólico, exposição a medicações teratogênicas e exposição a agentes infecciosos. Isto traz para discussão a importância da realização correta da assistência ao pré-natal.

As consultas pré-natais objetivam promover a orientação da mulher para melhor conduzir a gestação, bem como propiciar o tratamento de doenças existentes na mãe, em especial, aquelas que podem levar a comprometimento fetal, assim como proporciona para a criança a ser gerada: prevenção, diagnóstico e tratamento de doenças fetais. Dentre tais, enfatizam-se, nesta pesquisa, as malformações, que, em alguns casos, nas fases iniciais, é possível tratamento intrauterino ${ }^{21}$ que pode proporcionar uma vida normal e saudável para o recém-nascido. Pode-se observar uma evolução na assistência ao pré-natal quanto a sua cobertura, fato que é apontado em estudos realizados entre os anos de $2016^{22}$ e $2017 .{ }^{23}$ Esse avanço pode ter influenciado na diminuição da incidência dos óbitos devido às MCSN investigadas nesse estudo, através da prevenção, diagnóstico e tratamento mais precoce de doenças, e, ainda, através da promoção de saúde, por meio da educação em saúde.

A distribuição temporal dos óbitos por microcefalia destaca-se dos demais por apresentar comportamento atípico. Nos dados obtidos, a microcefalia apresentou-se como 
segunda MCSN que resultou em mais óbitos no Brasil, no período estudado. Contudo, é importante destacar que as frequências de óbitos dos anos entre 2000 e 2014 pouco variaram entre si, e que apenas em 2015 houve um crescimento súbito no número de casos, com um elevado pico no ano de 2016. Tal fato pode ser explicado pelo evento da epidemia do Zika virus ocorrido no Brasil em 2015. Oliveira ${ }^{24}$ considera que os primeiros meses de gestação das crianças que nasceram com microcefalia corresponderam ao período de maior circulação do Zika virus na região Nordeste e que não havia correlação com histórico de doença genética na família ou exames com padrão de outros processos infecciosos conhecidos. $^{24}$

Destaca-se, ainda, que a linha de incidência dos óbitos por microcefalia observada decaiu subitamente após o surto de 2016. Tal fato pode ser explicado pela quebra do ciclo de transmissão do Zika virus na população do país, resultado da aquisição de memória imunológica contra o agente infeccioso do Zika virus, pelos indivíduos previamente infectados, bem como pela melhoria das ações de prevenção e controle. ${ }^{25}$

Mesmo que não tenha sido vista relação estatística significante entre o número de óbitos por MCSN e a escolaridade da mãe, pode-se observar crescimento acentuado da mortalidade do nível de escolaridade 0 a 3 anos para o de 4 a 11 anos. De acordo com o SINASC, 71\% das mulheres da faixa etária de mulheres de 19 a 35 possuem escolaridade de 4 a 11 anos, $^{10}$ sendo uma possível explicação para o aumento de óbitos analisado. Ainda se pode verificar uma queda abrupta na mortalidade por MCSN de filhos com mães com nível de escolaridade de 12 ou mais anos quando comparado com as de 4 a 11 anos. Uma das hipóteses é que quanto maior o grau de escolaridade das mães, maior é assiduidade nas consultas pré-natais, melhor entendimento a despeito das informações relacionados à gestação, e maior nível de renda que pode estar associado a melhores condições de acesso a bens e serviços mais protetores a MCSN. ${ }^{10}$

Não obstante, apesar dos resultados aqui observados, convém ressaltar algumas das suas limitações. A primeira é a possibilidade de existência de casos subnotificados ou que simplesmente não foram registrados com a causa do óbito na Declaração de Óbito (DO). Além disso, outro impasse encontrado foi a maneira de determinação da causa do óbito, tendo em vista que algumas classificações se tornam abrangentes para uma grande quantidade de MCSN, interferindo assim no resultado das causas específicas de óbitos por MCSN. Outra limitação se deve à incompletude dos dados de várias variáveis sociodemográficas, principalmente sexo, raça/cor, escolaridade materna e idade da mãe relacionadas aos óbitos. O fato que comprova esta incompletude dos dados pode ser verificado para a informação da idade e escolaridade materna, pois 30,7\% e 37,0\% dos casos, respectivamente, não tinham o registro dessas informações relacionadas aos óbitos por 
MCSN. Essa situação reflete a precariedade e desorganização dos serviços de saúde na adequada coleta das informações registradas nas DO. Com isso, podem estar prejudicadas a interpretação da realidade epidemiológica desse agravo e das associações em estudo. A melhora na coleta dos dados das variáveis citadas auxiliaria na construção de um melhor banco de dados, o que poderia gerar estudos cada vez mais específicos e relevantes, facilitando a mobilização governamental para modificar a realidade.

Porém, este estudo tem importante relevância para a saúde no Brasil, pois debate importantes patologias que, frequentemente, culminam em óbitos, especialmente em crianças menores de um ano, o que impacta a estatística brasileira de mortalidade infantil. Além disso, se trata de análise de dados coletados em um intervalo de tempo de 18 anos com comparações entre todas as regiões do Brasil, tornando possível observação abrangente sobre a situação dos óbitos por MCSN e da saúde materno-infantil no Brasil neste século XXI.

\section{Conclusão}

Verificou-se que há grande ocorrência de óbitos por malformação congênita do sistema nervoso e, apesar de em números absolutos no Brasil ter ocorrido decréscimo, estes ainda se mantêm elevados. Contudo, medidas de sociais e de saúde podem auxiliar na melhora do atual panorama, visto que algumas dessas malformações podem ser prevenidas através de aconselhamento genético e especialmente do pré-natal. O Brasil é um país em desenvolvimento que ainda possui um grande contingente populacional de adultos com baixo nível de escolaridade, com problemas socioeconômicos e com pouca orientação quanto à saúde. Isso se reflete na baixa adesão ao pré-natal e cuidados gestacionais, assim como questões importantes durante puerpério e atenção ao desenvolvimento infantojuvenil.

Tendo isso em vista, faz-se necessário reforçar a ampliação da cobertura da atenção primária e acesso às redes de serviços especializados, visto que é inegável o benefício disso para a gestação e para o desenvolvimento fetal. Cabe ainda ressaltar a necessidade da realização de estudos que investiguem os óbitos por MCSN e as variáveis demográficas e socioeconômicas envolvidas, especialmente de forma mais direta através de dados primários.

\section{Referências}

1. Organização Pan-Americana de Saúde. Prevenção e controle de enfermidades genéticas e os defeitos congênitos: relatório de um grupo de consulta. Washington, DC: OPAS; 1984. 
2. Campos DA, Peixoto MSRM, Medeiros BGS, Lucena VS. Fatores genéticos: prevalência de mortalidade neonatal e anomalias congênitas. J Biol Pharm Agric Manag. 2017;13(2):1-10.

3. Mendes IC, Jesuino RSA, Pinheiro DDS, Rebelo ACS. Anomalias congênitas e suas principais causas evitáveis: uma revisão. Rev Med Minas Gerais. 2018;28:e-1977. http://www.dx.doi.org/10.5935/2238-3182.20180011.

4. Barros ML, Fernandes DA, Melo EVD, Porto RLS, Maia MCA, Godinho AS, et al. Malformações do sistema nervoso central e malformações associadas diagnosticadas pela ultrassonografia obstétrica. Radiol Bras. 2012;45(6):309-14.

5. Marcdante KJ, Kliegman RM. Nelson: Princípios de pediatria. 7a ed. Rio de Janeiro: Elsevier; 2017.

6. Campos Júnior D, Burns DAR, Lopez FA, organizadores. Tratado de pediatria. 4a ed. [São Paulo]: Ed. Manole; 2017. 2 vol.

7. Pereira-Mata R, Franco A, Gago C, Pacheco A. Prenatal diagnosis of neural tube defects. Acta Obstet Ginecol Port. 2018;12(2):134-44.

8. Albuquerque MFPM, Souza WV, Araújo TVB, Braga MC, Miranda Filho DB, Ximenes RAA, et al. Epidemia de microcefalia e vírus Zika: a construção do conhecimento em epidemiologia. Cad Saude Publica. 2018;34(10):e00069018. https://doi.org/10.1590/0102-311X00069018.

9. Brasil. Resolução n. 510, de 07 de abril de 2016. Dispõe sobre as normas aplicáveis a pesquisas em Ciências Humanas e Sociais. Brasília, DF: Diário Oficial [da] União; 2016 maio 24 [citado 2020 jun. 20]. Disponível em: http://bit.ly/2fmnKeD.

10. Tabnet: banco de dados do Sistema Único de Saúde [Internet]. [Brasília, DF]: Ministério da Saúde; [c2020 citado 1 mar 2020]. Disponível em: http://tabnet.datasus.gov.br/cgi/deftohtm.exe?sinasc/cnv/nvuf.def.

11. Verma M, Chhatwal J, Singh D. Congenital malformations: a retrospective study of 10,000 cases. Indian J Pediatr. 1991;58(2):245-52. https://doi.org/10.1007/BF02751129.

12. Nazer J, Cifuentes L, Rodríguez M, Rojas M. Malformaciones del sistema nervioso central en el Hospital Clínico de la Universidad de Chile y maternidades chilenas participantes en el Estudio Colaborativo Latinoamericano de Malformaciones Congénitas (ECLAMC). Rev Med Chile. 2001;129(10):1163-70. http://dx.doi.org/10.4067/S0034-98872001001000008. 
13. Melo WAD, Zurita RCM, Uchimura TT, Marcon SS. Anomalias congênitas: fatores associados à idade materna em município sul brasileiro, 2000 a 2007. Rev Eletr Enferm. 2010;12(1). http://dx.doi.org/10.5216/ree.v12i1.5994.

14. Senesi LG, Tristão EG, Andrade RP, Krajden ML, Oliveira Junior FC, Nascimento DJ. Morbidade e mortalidade neonatais relacionadas à idade materna igual ou superior a 35 anos, segundo a paridade. Rev.Bras Ginecol Obstet. 2004;26(6):477-82. http://dx.doi.org/10.1590/S0100-72032004000600009.

15. Magalhães MLC, Furtado FM, Nogueira MB. Gestação na adolescência precoce e tardia: há diferença nos riscos obstétricos? Rev Bras Ginecol Obstet. 2006;28(8):446-52. https://doi.org/10.1590/S0100-72032006000800002.

16. Souza ASR, Amorim MMR, Porto AMF. Condições frequentemente associadas com cesariana, sem respaldo científico. Femina. 2010;38(10):505-16.

17. Penn Z, Ghaem-Maghami S. Indications for caesarean section. Best Pract Res Clin Obstet Gynaecol. 2001;15(1):1-15. https://doi.org/10.1053/beog.2000.0146.

18. Blog da Saúde (BR). Ministério da Saúde e ANS publicam regras para estimular parto normal na saúde suplementar [Internet]. [Brasília, DF]: MS; 2015 jan. 6 [citado 2015 fev. 15]. Disponível em: http://www.blog.saude.gov.br/c1v7/4.

19. Instituto Brasileiro de Geografia e Estatística. Indicadores sociodemográficos e de saúde no Brasil. Rio de Janeiro: IBGE; 2009.

20. Dal Fabbro, M. Estudo da evolução e prognostico comparativos de neonatos com hidrocefalia congênita isolada ou associada a defeitos do fechamento do tubo neural [dissertação]. [Campinas]: Universidade Estadual de Campinas; 2008.

21. Ministério da Saúde (BR). Atenção ao pré-natal de baixo risco. Brasília, DF: MS; 2012. (Cadernos de atenção básica).

22. Nunes JT, Gomes KRO, Rodrigues MTP, Mascarenhas MDM. Qualidade da assistência prénatal no Brasil: revisão de artigos publicados de 2005 a 2015. Cad Saude Colet. 2016;24(2):252-61. https://doi.org/10.1590/1414-462X201600020171.

23. Nunes ADS, Amador AE, Dantas APQ, Azevedo UN, Barbosa IR. Acesso à assistência prénatal no Brasil: análise dos dados da Pesquisa Nacional de Saúde. Rev Bras Promocao Saude. 2017;30(3):1-10. https://doi.org/10.5020/18061230.2017.6158. 
24. Nunes ML, Carlini CR, Marinowic D, Neto FK, Fiori HH, Scotta MC, et al. Microcefalia e vírus Zika: um olhar clínico e epidemiológico do surto em vigênciano Brasil. J Pediatr. 2016;92(3):230-40. http://dx.doi.org/10.1016/j.jped.2016.02.009.

25. Garcia LP. Epidemia do vírus Zika e microcefalia no Brasil: emergência, evolução e enfrentamento. Brasília, DF: IPEA; 2018. (Texto para discussão).

\section{Contribuições Autorais}

Mateus de Sousa Cavalcante - Concepção, planejamento, análise, interpretação, redação, e revisão do trabalho; Glaucia Galindo Silva - Concepção, planejamento, análise, interpretação, e redação do trabalho; Érica Santos Rocha - Concepção, planejamento, análise, interpretação, redação, e revisão do trabalho. Jardel Barbosa da Silva - Concepção, planejamento, análise, interpretação e redação do trabalho; Thayná Rocha Coimbra - Concepção, planejamento, análise, interpretação e redação do trabalho; Allan Cristhyan Alves Carvalho - Planejamento, análise, interpretação, redação e revisão do trabalho; e Bruno Luciano Carneiro Alves de Oliveira - Orientação, concepção, planejamento, análise, interpretação e revisão do trabalho. 


\section{Minicurrículo}

Mateus Sousa Cavalcante | ORCiD: 0000-0002-2245-0286

Acadêmico do curso de medicina da Universidade Federal do Ceará - UFC, Campus em Sobral, CE, Brasil.

Glaucia Galindo Silva | ORCiD: 0000-0002-2596-889X

Acadêmica do curso de medicina da Universidade Federal do Maranhão - UFMA, Campus em Pinheiro, MA, Brasil.

Érica Santos Rocha | ORCiD: 0000-0002-3221-2273

Acadêmica do curso de medicina da Universidade Federal do Maranhão - UFMA, Campus em Pinheiro, MA, Brasil.

Jardel Barbosa da Silva | ORCiD: 0000-0002-2777-5127

Acadêmico do curso de medicina da Universidade Federal do Maranhão - UFMA, Campus em Pinheiro, MA, Brasil.

Thayná Rocha Coimbra | ORCiD: 0000-0002-6920-3637

Acadêmica do curso de medicina da Universidade Federal do Maranhão - UFMA, Campus em Pinheiro, MA, Brasil.

Allan Cristhyan Alves Carvalho | ORCiD: 0000-0002-5539-6917

Acadêmico do curso de medicina da Universidade Federal do Ceará - UFC, Campus em Sobral, CE, Brasil.

Bruno Luciano Carneiro Alves de Oliveira | ORCiD: 0000-0001-8053-7972

Enfermeiro. Doutorado em Saúde Coletiva. Docente do curso de medicina da Universidade Federal do Maranhão - UFMA, São Luís, MA, Brasil e do Programa de Pós-graduação em Saúde Coletiva - PPGSC UFMA. 